http://jmscr.igmpublication.org/home/ ISSN (e)-2347-176x ISSN (p) 2455-0450

crossref DOI: https://dx.doi.org/10.18535/jmscr/v8i3.37

\author{
Journal Of Medical Science And Clinical Research \\ IGM Publication \\ An official Publication of IGM Publication
}

\title{
Original Research Article \\ Cross-sectional study to compare the clinical features in low normal versus high normal plasma glucose levels in euglycemic individuals
}

\author{
Authors \\ Dr Vinod Verma ${ }^{1}$, Dr Dharmendra Jhavar ${ }^{2}$, Dr Umesh Kumar Chandra ${ }^{3}$ \\ ${ }^{1,3}$ Senior Resident, ${ }^{2}$ Professor, Department of Medicine, MGM Medical College and MY Hospital, Indore, MP, India \\ Corresponding Author \\ Dr Dharmendra Jhavar \\ Professor, Department of Medicine, MGM Medical College and MY Hospital, Indore, MP, India
}

\begin{abstract}
Introduction: It has been known that the diagnosis of diabetes should be made early to prevent cardiovascular and other metabolic complications. So far, determination of blood glucose levels has been used to diagnose diabetes. It shows why the glucose-centric definition for diagnosing diabetes that has been used so far could not be applied to the sole diagnosis criteria for a group of patients with such "syndrome".
\end{abstract}

Materials and Methods: This cross sectional study was carried out in the department of medicine, M.G.M. Medical College and M.Y. Hospital Indore from July 2016 to August 2017 in 200 individuals and patients having euglycemic status attending General Medicine OPD.

Results: The mean BMI in the low normal group was $23.79 \pm 1.09 \mathrm{~kg} / \mathrm{m}^{2}$ and in the high normal group it was $24.43 \pm 1.26 \mathrm{~kg} / \mathrm{m}^{2}$. The difference was found to be statistically significant $(P<0.05)$. In the low normal group, of the females, 40(80\%) were having normal W:H ratio and 10(20\%) were having abnormal W:H ratio. In males, only 5(10\%) were having abnormal W:H ratio. In the high normal group, in females $15(33.3 \%)$ were having abnormal W:H ratio. In males, $19(34.5 \%)$ were having abnormal W:H ratio. In $100(100 \%)$ patients of both the groups, the fundus findings were found to be normal.

Conclusions: It can be concluded that higher values of BMI, Waist-Hip Ratio and positive family history for diabetes were found more commonly associated with high normal euglycemic group when compared with low normal euglycemic group.

Keywords: Body Mass Index, Euglycemia, Waist Hip Ratio.

\section{Introduction}

It has been known that the diagnosis of diabetes should be made early to prevent cardiovascular and other metabolic complications. So far, determination of blood glucose levels has been used to diagnose diabetes. As a matter of fact, some diabetic patients had already had chronic complication at the first time of diagnosis. It shows why the glucose-centric definition for diagnosing diabetes that has been used so far could not be applied to the sole diagnosis criteria for a group of patients with such "syndrome".

Blood glucose measurements and the cut-off point for diagnosing diabetes have become controversial debates for a long time. In 1979, the National Diabetes Data Group (NDDG) made diagnostic criteria for diabetes, which subsequently have been used for over 2 decades. At that time, the Committee used the cut-off point of blood glucose level based on distribution and it was not 
associated with the correlation between blood glucose levels and chronic complication. Diagnosis of diabetes was established when fasting plasma glucose levels (FPG) $>140 \mathrm{mg} / \mathrm{dl}$; 2-hour post-prandial blood glucose or 2-hours PPG > $200 \mathrm{mg} / \mathrm{dl}^{[1-5]}$

Since a long time ago, the experts have realized that determination of cut-off point for diagnosing diabetes will be revised over time with the lower blood glucose levels as the more sensitive diagnosis for detecting the occurring complication.

\section{Materials and Methods}

This cross sectional study was carried out in the department of medicine, M.G.M. Medical College and M.Y. Hospital Indore from July 2016 to August 2017. We included 200 individuals and patients having euglycemic status attending General Medicine OPD, Endocrine OPD and Medicine Wards.

We arbitrarily divided fasting euglycemia into low normal below $<85 \mathrm{mg} / \mathrm{dl} \&$ high normal ranging from $86-100 \mathrm{mg} / \mathrm{dl}$ and post prandial euglycemia into low normal ranging from $<120 \mathrm{mg} / \mathrm{dl}$ and high normal ranging from 121-140 mg/dl. All patients or legally acceptable representative provided written inform consent for participation. The research protocol and informed consent form was approved by scientific review committee.

\section{Inclusion Criteria}

- All consenting individuals found to be euglycemic.

- Age group: adult population of $18-60$ years

\section{Exclusion criteria}

- Known case of Diabetes.

- Patients not giving consent.

- Patients on drugs causing hypoglycemia (e.g. Beta-blockers, Haloperidol, Quinidine, MAO inhibitors etc.).

- Patients on drugs causing hyperglycemia (e.g. Corticosteroids, Fluoroquinolones, thiazide and thiazide like drugs etc.).
Patients included in the study were subjected to full history including family history for Diabetes and Hypertension. Then patient is examined clinically and hemodynamically. Blood samples were withdrawn and investigations planned were done and if patient/ individual is found to be euglycemic, he/she is included in the study after his/her consent. Fundus was examined for Diabetic retinopathy changes.

\section{Statistical Methods}

Data were prospectively collected and coded prior to analysis using the professional statistical Package for Social Science (SPSS) software. The description of data was in the form of mean $( \pm)$ SD for quantitative data and frequency and proportion for qualitative data. Unpaired ' $t$ ' test $(t)$ applied was used for comparison between two groups regarding normally distributed (parametric) quantitative data. Results were considered significant if $\mathrm{P}<0.05$.

\section{Results}

This cross sectional study was carried out in the department of medicine, M.G.M. Medical College and M.Y. Hospital Indore from July 2016 to August 2017. We included 200 individuals and patients having euglycemic status.

As shown in table 1, in the low normal group, there were $10(10 \%)$ patients in the age group 1820 years, $21(21 \%)$ in the age group 21-30 years, $26(26 \%)$ in the age group 31-40 years, $23(23 \%)$ in the age group 41-50 years and 20(20\%) in the age group 51-60 years. In the high normal group, there were $9(9 \%)$ patients in the age group 18-20 years, $25(25 \%)$ in the age group 21-30 years, $25(25 \%)$ in the age group $31-40$ years, $18(18 \%)$ in the age group 41-50 years and 23(23\%) in the age group 51-60 years. The mean age in the low normal group was $37.55 \pm 12.51$ years and in the high normal group it was $38.44 \pm 2.95$ years. The difference was found to be statistically not significant $(\mathrm{P}>0.05)$, showing that the age is comparable between the two groups. 
Table 1: Distribution of patients according to age

\begin{tabular}{|c|c|c|c|c|}
\hline \multirow[t]{2}{*}{ Age Group } & \multicolumn{2}{|c|}{$\begin{array}{l}\text { Low Normal Group } \\
\text { FBS } \leq 85, \text { PPBS } \leq 120\end{array}$} & \multicolumn{2}{|c|}{$\begin{array}{l}\text { High Normal Group } \\
\text { FBS }>85, \text { PPBS }>120\end{array}$} \\
\hline & No. & $\%$ & No. & $\%$ \\
\hline $18-20$ years & 10 & 10.0 & 9 & 9.0 \\
\hline 21-30 years & 21 & 21.0 & 25 & 25.0 \\
\hline $31-40$ years & 26 & 26.0 & 25 & 25.0 \\
\hline $41-50$ years & 23 & 23.0 & 18 & 18.0 \\
\hline $51-60$ years & 20 & 20.0 & 23 & 23.0 \\
\hline Total & 100 & 100.0 & 100 & 100.0 \\
\hline Mean \pm SD & \multicolumn{2}{|c|}{$37.55 \pm 12.51$} & \multicolumn{2}{|c|}{$38.44 \pm 12.95$} \\
\hline ' $t$ ' value & \multicolumn{4}{|c|}{$-0.494, \mathrm{df}=198$} \\
\hline$P$ value & \multicolumn{4}{|c|}{$0.622, \mathrm{NS}$} \\
\hline
\end{tabular}

As shown in table 2, in the low normal group, there were 50(50\%) females and 50(50\%) males, while in the high normal group there were $45(45 \%)$ female and 55(55\%) males. In the low normal group, in $95(95 \%)$ patients there was negative family history for diabetes mellitus, while in $5(5 \%)$ patients there was a positive family history for diabetes mellitus.

Table 2: Distribution of patients according to gender

\begin{tabular}{|l|c|c|c|c|}
\hline \multirow{2}{*}{ Gender } & \multicolumn{2}{|c|}{$\begin{array}{c}\text { Low Normal Group } \\
\text { FBS } \leq \mathbf{8 5}, \text { PPBS } \leq \mathbf{1 2 0}\end{array}$} & \multicolumn{2}{c|}{$\begin{array}{c}\text { High Normal Group } \\
\text { FBS }>\text { 85, PPBS }>\mathbf{1 2 0}\end{array}$} \\
\cline { 2 - 5 } & No. & $\mathbf{\%}$ & No. & \% \\
\hline Female & 50 & 50.0 & 45 & 45.0 \\
\hline Male & 50 & 50.0 & 55 & 55.0 \\
\hline Total & 100 & 100.0 & 100 & 100.0 \\
\hline
\end{tabular}

As shown in table 3, in the low normal group, in 95(95\%) patients there was negative family history for diabetes mellitus, while in $5(5 \%)$ patients there was a positive family history for diabetes mellitus. In the high normal group, in
$85(85 \%)$ patients there was negative family history for diabetes mellitus, while in $15(15 \%)$ patients there was a positive family history for diabetes mellitus.

Table 3: Distribution of patients according to family history of diabetes mellitus

\begin{tabular}{|l|c|c|c|c|}
\hline \multirow{2}{*}{$\begin{array}{l}\text { Family History of } \\
\text { Diabetes Mellitus }\end{array}$} & \multicolumn{2}{|c|}{$\begin{array}{c}\text { Low Normal Group } \\
\text { FBS } \leq \mathbf{8 5}, \text { PPBS } \leq \mathbf{1 2 0}\end{array}$} & \multicolumn{2}{c|}{$\begin{array}{c}\text { High Normal Group } \\
\text { FBS }>\text { 85, PPBS }>\mathbf{1 2 0}\end{array}$} \\
\cline { 2 - 5 } & No. & \% & No. & \% \\
\hline Negative & 95 & 95.0 & 85 & 85.0 \\
\hline Positive & 5 & 5.0 & 15 & 15.0 \\
\hline Total & 100 & 100.0 & 100 & 100.0 \\
\hline
\end{tabular}

As shown in table 4, in 100(100\%) patients of both the groups, the fundus findings were found to be normal. Table 4: Distribution of patients according to Fundus findings

\begin{tabular}{|l|c|c|c|c|}
\hline \multirow{2}{*}{$\begin{array}{l}\text { Fundus } \\
\text { findings }\end{array}$} & \multicolumn{2}{|c|}{$\begin{array}{c}\text { Low Normal Group } \\
\text { FBS } \leq \mathbf{8 5}, \mathbf{P P B S} \leq \mathbf{1 2 0}\end{array}$} & \multicolumn{2}{c|}{$\begin{array}{c}\text { High Normal Group } \\
\text { FBS }>\mathbf{8 5}, \text { PPBS }>\mathbf{1 2 0}\end{array}$} \\
\cline { 2 - 5 } & No. & $\mathbf{\%}$ & No. & \% \\
\hline Normal & 100 & 100.0 & 100 & 100.0 \\
\hline Abnormal & 0 & 0.0 & 0 & 0.0 \\
\hline Total & 100 & 100.0 & 100 & 100.0 \\
\hline
\end{tabular}

As shown in table 5, distribution of patients according to $\mathrm{W}: \mathrm{H}$ Ratio. In the females $\mathrm{W}: \mathrm{H}$ ratio of $<0.85$ and in males $<0.91$ was taken as normal. In the low normal group, in females, $40(80 \%)$ 
were having normal $\mathrm{W}: \mathrm{H}$ ratio and $10(20 \%)$ were having abnormal $\mathrm{W}: \mathrm{H}$ ratio. In males, $45(90 \%)$ were having normal $\mathrm{W}: \mathrm{H}$ ratio and only $5(10 \%)$ were having abnormal $\mathrm{W}: \mathrm{H}$ ratio. In the high normal group, in females, 30(66.7\%) were having normal $\mathrm{W}: \mathrm{H}$ ratio and $15(33.3 \%)$ were having abnormal $\mathrm{W}: \mathrm{H}$ ratio. In males, 36(65.5\%) were having normal $\mathrm{W}: \mathrm{H}$ ratio and $19(34.5 \%)$ were having abnormal $\mathrm{W}: \mathrm{H}$ ratio.

Overall in the low normal group, there were $85(85 \%)$ patients with normal $\mathrm{W}: \mathrm{H}$ ratio and
$15(15 \%)$ with abnormal $\mathrm{W}: \mathrm{H}$ ratio, in the high normal group, there were 66(66\%) patients having normal $\mathrm{W}: \mathrm{H}$ ratio and $34(34 \%)$ were having abnormal $\mathrm{W}: \mathrm{H}$ ratio. The proportional comparison between the two groups for overall abnormal $\mathrm{W}: \mathrm{H}$ ratio was found to be statistically significant $(\mathrm{P}<0.05)$, showing a higher proportion of patients in the high normal group to be having abnormal $\mathrm{W}: \mathrm{H}$ ratio in comparison to the low normal group.

Table 5: Distribution of patients according to W:H Ratio

\begin{tabular}{|l|c|c|c|c|c|}
\hline \multirow{3}{*}{ Gender } & $\begin{array}{c}\text { Normal/ } \\
\text { Abnormal }\end{array}$ & \multicolumn{2}{c|}{$\begin{array}{c}\text { Low Normal Group } \\
\text { FBS } \leq \mathbf{8 5}, \text { PPBS } \leq \mathbf{1 2 0}\end{array}$} & \multicolumn{2}{c|}{$\begin{array}{c}\text { High Normal Group } \\
\text { FBS }>\text { 85, PPBS }>\mathbf{1 2 0}\end{array}$} \\
\cline { 3 - 6 } & & $\mathbf{N o .}$ & $\mathbf{\%}$ & No. & \% \\
\hline \multirow{2}{*}{ Female } & Normal & 40 & 80.0 & 30 & 66.7 \\
\cline { 2 - 6 } & Abnormal & 10 & 20.0 & 15 & 33.3 \\
\hline \multirow{2}{*}{ Male } & Normal & 45 & 90.0 & 36 & 65.5 \\
\cline { 2 - 6 } & Abnormal & 5 & 10.0 & 19 & 34.5 \\
\hline \multirow{2}{*}{ Overall } & Normal & 85 & 85.0 & 66 & 66.0 \\
\cline { 2 - 6 } & Abnormal & 15 & 15.0 & 34 & 34.0 \\
\hline Total & & 100 & 100.0 & 100 & 100.0 \\
\hline
\end{tabular}

$\mathrm{Z}($ Overall abnormal $)=-3.20, \mathrm{P}$ value $=0.001$, Significant

As shown in table 6, in the low normal group, there were $89(89 \%)$ patients with BMI $\leq 25.0$ $\mathrm{kg} / \mathrm{m}^{2}$ and $11(11 \%)$ with BMI $>25.0 \mathrm{~kg} / \mathrm{m}^{2}$. In the high normal group, there were $69(69 \%)$ patients with BMI $\leq 25.0 \mathrm{~kg} / \mathrm{m}^{2}$ and $31(31 \%)$ with BMI $>25.0 \mathrm{~kg} / \mathrm{m}^{2}$. The mean BMI in the low normal group was $23.79 \pm 1.09 \mathrm{~kg} / \mathrm{m}^{2}$ and in the high normal group it was $24.43 \pm 1.26 \mathrm{~kg} / \mathrm{m}^{2}$. The difference was found to be statistically significant $(\mathrm{P}<0.05)$, showing a higher $\mathrm{BMI}$ in the high normal group in comparison to the low normal group.

Table 6: Distribution of patients according to BMI

\begin{tabular}{|l|c|c|c|c|}
\hline \multirow{2}{*}{ BMI } & \multicolumn{2}{|c|}{$\begin{array}{c}\text { Low Normal Group } \\
\text { FBS } \leq \mathbf{8 5}, \text { PPBS } \leq \mathbf{1 2 0}\end{array}$} & $\begin{array}{c}\text { High Normal Group } \\
\text { FBS }>\text { 85, PPBS }>\mathbf{1 2 0}\end{array}$ \\
\cline { 2 - 5 } & No. & \% & No. & \% \\
\hline$<=25.0 \mathrm{~kg} / \mathrm{m}^{2}$ & 89 & 89.0 & 69 & 69.0 \\
\hline$>25.0 \mathrm{~kg} / \mathrm{m}^{2}$ & 11 & 11.0 & 31 & 31.0 \\
\hline Total & 100 & 100.0 & 100 & 100.0 \\
\hline Mean \pm SD & \multicolumn{3}{|c|}{$23.79 \pm 1.09$} & $24.43 \pm 1.26$ \\
\hline 't' value & \multicolumn{3}{|c|}{$0.024, \mathrm{df}=198$} \\
\hline P value & \multicolumn{3}{|c|}{$0.00 *$} \\
\hline
\end{tabular}

Unpaired ' $\mathrm{t}$ ' test applied. P value $=0.000$, Significant

\section{Discussion}

This cross sectional study was carried out in the department of medicine, M.G.M. Medical College and M.Y. Hospital Indore from July 2016 to August 2017. We included 200 individuals and patients having euglycemic status.
A total number of 200 subjects were selected for the study. We arbitrarily divided fasting euglycemia into low normal below $\leq 85 \mathrm{mg} / \mathrm{dl} \&$ high normal ranging from $86-100 \mathrm{mg} / \mathrm{dl}$ and post prandial euglycemia into low normal ranging from $\leq 120 \mathrm{mg} / \mathrm{dl}$ and high normal ranging from 121 - 
$140 \mathrm{mg} / \mathrm{dl}$. The subjects were divided into 2 groups on the basis of above criteria into low normal and high normal euglycemic state. Each group included 100 cases of low normal and high normal euglycemic status. In each group patients were divided in five age subgroups (18-20, 21-30, 31-40, 41-50, 51-60) in years.

Both groups were compared on various clinical (BMI, Waist-Hip ratio, Fundus examination and Systemic examination). Data evaluation was done using SPSS software. The results were expressed as Mean (standard deviation). The $\mathrm{P}$ value was used to compare the different groups.

In our study we found that BMI and Waist-Hip Ratio were on higher side in high normal euglycemic individuals. Diabetic retinopathy changes were not found in any individuals in either of the group and the systemic examination was found to be normal in all individuals. $P$ value was found to be significant in high normal euglycemic group in Waist-Hip Ratio and BMI. Our study showed that the markers of metabolic syndrome like Waist-Hip Ratio and BMI were more in high normal euglycemic individuals suggesting that the individuals in high normal euglycemic group are at risk of developing diabetes and metabolic complications, cardiovascular complications in future. ${ }^{[6]}$ On the basis of these findings we can advise interventions like - health education, life style modification, weight reduction and restrictions and modifications in dietary Habits to prevent complications of metabolic syndrome. In addition, future screening for diabetes and other complications can be advised. Diabetes is considered a coronary heart disease (CHD)- risk equivalent and it is frequently associated with various other cardiovascular $(\mathrm{CV})$ risk factors. ${ }^{[7]}$ Approximately, $80 \%$ of deaths in patients with diabetes are attributable to cardiovascular disease. According to Global Diabetes Community, obesity is believed to account for $80-85 \%$ of the risk of developing type 2 diabetes, while recent research suggests that obese people are up to 80 times more likely to develop type 2 diabetes than those with a BMI of less than 22. Studies suggest that abdominal fat causes fat cells to release 'proinflammatory' chemicals, which can make the body less sensitive to the insulin it produces by disrupting the function of insulin responsive cells and their ability to respond to insulin. This is known as insulin resistance - the hallmark of type 2 diabetes. Having excess abdominal fat (i.e. a large waistline) is known as central or abdominal obesity, a particularly high-risk form of obesity. In our study, also BMI and Waist-Hip Ratio were found to be on higher side in high normal euglycemic individuals when compared with low normal euglycemic individuals.

\section{Conclusion}

It can be concluded that higher values of BMI, Waist-Hip Ratio and positive family history for diabetes were found more commonly associated with high normal euglycemic group when compared with low normal euglycemic group.

\section{Declaration}

Funding: No funding source

Conflict of Interest: Not declared

Ethical Approval: Study was approved by Institutional Review Board.

\section{References}

1. Rushforth NB, Miller M, Bennett PH. Fasting and two-hour post-load glucose levels for the diagnosis of diabetes: the relationship between glucose levels and complications of diabetes in the Pima Indians. Diabetol. 1979;16:373-9.

2. National Diabetes Data Group. Classification and diagnosis of diabetes mellitus and other categories of glucose intolerance. Diabetes. 1979;28:1039-57.

3. Jarrett RJ, Keen H. Hyperglycaemia and diabetes mellitus. Lancet. 1976;1:1009-11.

4. Sayegh HAI, Jarrett RJ. Oral glucose tolerance tests and the diagnosis of diabetes: results of a prospective study based on the Whitehalll Survey. Lancet. 1979;2:431-3. 
5. Pettitt DJ,Knowler WC, Lisse, Bennett PH. Development of retinopathy and proteinuria in relation to plasma-glucose consentrations in Pima Indians. Lancet. 1980;2:1050-2.

6. Dale AC, Vatten LJ, Nilsen TI, Midthjell $\mathrm{K}$, Wiseth R. Secular decline in mortality from coronary heart disease in adults with diabetes mellitus: cohort study. Br Med J 2008; 337:236.

7. Libby P. Current concepts of the pathogenesis of the acute coronary syndromes. Circulation 2001; 104: 365372. 